25

THE ANNUAL MEETING: A FOUR YEAR STUDY. George D. Comerc1, Michae $1 \mathrm{~W}$. Cohen and Elizabeth W. Preece. ment of Pediatrics and office of Continuing Medical Education, Tucson, Arizona. (Spon, by Vincent A. Fulginiti)

Professional organizations have a responsibility for program evaluation. This paper describes a method and reports evaluative data from 4 annual pediatric meetings. Three components were assessed: a general plenary sesston, special topic sessions, and workshops. Data from 2,008 evaluations were analyzed. and special topic presentations factors: method, appropriateness, organization, quality of visual aides, and adequacy of data base. Special topic sessions were also evaluated for: over-all quality, performance of the moderator, and opportunity for discussion. Workshop content was evaluated using 3 factors: quality, currentness, and relevance. Assessment of participant satisfaction was based on the followIng 9 descriptives: rewarding, encouraging, educational, should be repeated, organized, helpful, at participant's level, met participant's needs, and group orientation. Content evaluation was also accomplished by evaluator identification of major points made by the presenter or workshop leader. General and special topic presentations were judged "good"
with an average score of 3.0 based on a scale of 1 (poor) to 4 (excellent). Workshop satisfaction and content were both fudged "good" with respective average scores of 3.9 and 4.0 on a scale of 1 (poor) to 5 (excellent). Results are being used to effect changes In abstract selection performance of participants plan-

26 A FOUR YEAR LONGITUDINAL STUDY OF A PEDIATRIC CLERKSHIP. George D. Comerc1, V1ncent A. Fulginit1 and Pame la S. Brown. Univ. of Arizona Col. of Med., Dept. of Ped. and Office of Continuing Medical Education, Tucson, Az. clerkship performance should be evaluated to determine if objectives are achleved and appropriate and to improve the clerkship experience. Medical students (184) had a 12 week clerkship between 1969 and 1973. Emphasis was on data collection, problem solving, pediatric knowledge, and attitude in the clinical setting. Clerkship objectives, content and evaluation method were made known prior to the experience. Evaluation was done in the above emphasis areas. Student attitudes were quantifled using pre-established criteria. Students, upon completion of the clerkship and later as housestaff, were asked to permit 2 supervisors to evaluate their performance as housestaff. One hundred fifteen students responded and 153 evaluations were made by housestaff students responded and 153 evaluations were made by housestaff
supervisors. Performance was analyzed and comparisons made of supervisors. Performance was analyzed and comparisons made of
emphasis areas as well as between clerkship, housestaff, and $\mathrm{Na}$ emphasis areas as well as between clerkship, housestaff, and Na-
tional Board performances. Performance was compared to specialty choice and graduates indicated the degree of clerkship influence, If any, on their choice.

Achievement was documented by: National Boards (NB) (Pass: Clerkship-99\%/HS-97\%); evaluation of housestaff (HS) ( $96 \%$ no def1c1t in ped. knowledge, average or above performance: clerkship$79 \% / \mathrm{NB}-99 \%$ ); and retrospective assessment by HS (objectives highly appropriate $-47 \%$ and preparation expecially strong-61\%). There were notable differences in performances for varlous objectives and all except attitude corre lated with specialty choice (ped.

\section{GESTATIONAL AGE ESTIMATION IN SICK NEWBORNS} Cecella Daum, Diane Kurtzberg, Bruce Grellong, Susan Albin and Herbert Vaughan (Spon. by Lawrence Gartner), Departments of Pediatrics, Neurosclence and Psychlatry, Albert Einsteln College of Medicine, Bronx, New York

The Dubow1tz examination for estimation of gestational age 1s often difficult or Impossible to administer in its entirety In sick infants, especially those recelving ventilatory support. A shortened version of the examination has been devised which permits assessment of gestational age with minimal loss of predictive accuracy. The complete Dubowitz examination was administered to 112 infants from 29 to 42 weeks gestational age. Factor analysis and stepwise regression were performed to Identify the items that contributed preponderantly to the total varlance. Three non-discriminating items (edema, skin color, posture) were eliminated on the basis of these analyses, as well as three additional items (lanugo, head lag, ventral suspension) which cannot be assessed in infants on respirators. The shortened scale correlated highly with the total Dubowitz score ( $r$ - .985), providing an instrument which can be administered to seriously 111 infants with little loss of predictive accuracy ( $95 \%$ confidence 11 mit \pm 1 week).
28 NEUROBEHAVIORAL ASSESSMENT OF HIGH-RISK NEONATES Cecella Daum, Diane Kurtzberg, Bruce Grellong, Susan Albin and Herbert Vaughan (Spon. by Lawrence Gartner), Department of Pediatrics, Neuroscience and Psychiatry, Albert Einstein College of Medicine, Bronx, New York

A new examination has been developed which provides a rellable evaluation of neonatal neurological and behavioral organization, and is sensitive to Individual differences in neurobehavioral status at conceptional ages from 30 to 42 weeks. Items evaluate maturational level, sensorimotor status and functions thought to Involve cortical processing (1.e., visual tracking and auditory orienting)

Fifty normal full-term infants (NFT) were compared to 120 low-birth-we1ght (LBW) Infants ( 37 weeks gestational age, and/or welght < 10 percentile for age) tested at 40 weeks conceptional age. Interscorer rellability was .97 and test-retest rellability .91 . $78 \%$ of LBW Infants fell outside the range of NFT Infants on visual tracking and auditory orienting items. Head position preference thought to be an early expression of hemispheric dominance was overwhelmingly right-sided (90z) in the NFT group and substantially less so (49\%) in LBW infants. The LBW Infants as a group manifested significant deficits on active motility, and in complex reflexes (rooting and Moro), as well as a somewhat higher incidence of hypotonia and hypertonia. Items considered sensitive to deficient cortical functloning showed a strikingly greater disparity between LBW and NFT than did the standard neurological tests of motor and reflexive performance.

SYSGPAPHIA AND SUPERIOR INTCLLIGENCE: A PROCESSING SYIHDROME ? Ronald B. David and Rohart $H$. Willoughby (Sponsored by Harold ". Maurer). Menical colleae of virginia Nirginia Commonwealth Univ.. Univ. of virginia School iadicine, Jepts. of Pediatrics, Richmond and Charlottesville.

Six hoys, man ane 9.6 , presented with an unusual processing syndrome. All subjects were avaluated for schonl difficulties. a highly consistent psychoeducational proflle was found in all suijects. This consisted of superior verbal intelligence (mean I2 131) and highly discrepant performance skills (mean I? 105). In particular, performance skills ware found to he imnaired in the area of visual motor dexterity for sequential material. Sunplementary tests indicated disproportionately lower snelling and math scores. All displayed dysqraphic symptoms of a varying typa and degree with handwriting consequently por to illeqible and characterized by reversals, distortions and senuencino errors. Traditionally employed measures of perceptual motor intecration e.g. Bender-cestalt were, howcuer, age annropriate.

The findinas in this sample, though small, suqaest a process. ing syndrome consisting of high verbal-conceptual ahilities accompanied by dysgraphia. Whether the dysgrantia results from noor visual perception, visual memory, concentualization of written form, concention form-motor translation or pure fine motor difficulty is unknown. The data would howevnr tend to sugnest that the defect is either in visual memory or conceptualization of written form. Reliance on traditional tests of finure conyina are invalid screens for some dysgramhic children. Farly recoqimnortant so that their verbe and performance deficits remediated. \section{HEALTH VISITORS' ROLE IN PREDICTION OF EARLY} Janet G. Dean, Ian McQueen, Ross G. Mitchell, and C. Henry Kempe. University of Colorado Medical Center, Department of Pediatrics, Denver, and Untversity of Aberdeen, Scotland.

Health visitors (registered murses) in Aberdeen, Scotland, administered a brief "maternal attitude questlonnaire" and recorded a subjective assessment of mother-chlld interaction at age 3-4 months on all 7,700 births within the city. During the first two years of life, 1,388 $(20 \%)$ of these children presented with an injury or fallure to thrive (FTT). This Index group was matched at age 2 with chlldren from the original group who had no such findings. Within the index group, $76 \%$ were seen for accidents, $10 \%$ for overtly negligent injuries, and $14 \%$ for suspected non-accidental infury or FTT. The questionnalre revealed no signiflcant differences between the index and control groups; however, analysis of the health visitors' subjective assessments revealed that twice as many index children as control chlldren recelved assessments of "moderate" to "great concern." A comparison of outcome variables within the index group revealed that these ratings related signiflcantly to two variables: the higher the level of concern, the more likely an injury would be non-accidental and, within this group, the more likely an injury would be a serious hospitalized case. Of the total study population $(2,776), 10 \%(218)$ were rated as "moderate" to "great concern. " Two-thirds of these 218 chlldren later presented with Injurles or FTT which might have been prevented by intensive intervention. 